\title{
Traumatic renal artery occlusion in the pediatric age group: a case and review of the literature
}

\author{
Pediatrik yaş grubunda travmatik renal arter oklüzyonu: \\ Bir olgu ve literatürün gözden geçirilmesi
}

\author{
Saurabh GARGE, Ravi KANOJIA, KIn RAO
}

Blunt trauma represents a major cause of death in children. The incidence of renal arterial injuries in these cases is less than $1 \%$. Traumatic renal artery occlusion is a rare occurrence in the pediatric age group. However, there is lack of information on the exact incidence and results of the management of these rare cases in the pediatric age group. We report herein a case and we review the available literature of this severe injury in the pediatric age group.

Key Words: Traumatic renal artery occlusion; blunt trauma; children.
Künt travma çocuklarda başlıca ölüm nedenini oluşturmaktadır. Renal arter yaralanmalarının görülme sıklığı \%1'den düşüktür. Pediyatrik yaş grubunda travmatik renal arter oklüzyonu nadiren oluşmaktadır. Ancak, çocuk yaştaki bu nadir olguların kesin insidans ve tedavi sonuçları hakkında bilgi eksikliği vardır. Bu yazıda bir olgu sunuldu ve pediyatrik yaş grubunda bu ağır travmaya ilişkin mevcut literatür gözden geçirildi.

Anahtar Sözcükler: Travmatik renal arter oklüzyonu; künt travma; çocuk.
Traumatic renal artery occlusion in the pediatric age group is rare ${ }^{[1-3]}$ Children are more prone to these injuries owing to their anatomical vulnerability. ${ }^{[4]}$ The various studies reported in the literature dealing with the management of renal arterial injuries have included both pediatric and adult cases. The management guidelines have been the same for adult and pediatric cases. We reviewed the literature regarding these rare injuries with a pediatric perspective.

\section{CASE REPORT}

A four-year-old female presented to the emergency room with alleged history of accidental fall from a bike. She had been struck by a pole and presented as a case of blunt trauma to the abdomen. The patient was referred to us 48 hours after injury, during which time she was resuscitated in a peripheral hospital, where she was transfused two aliquots of blood and kept nil per os, on fluids. Clinically, the child was he- modynamically stable. On inspection of her abdomen, there was bruising present on the left flank. On palpation, it was soft with mild tenderness in the right hypochondrium, with no guarding or rigidity. Abdominal radiograph was normal. Ultrasound of the abdomen showed grade 3 left renal injury with associated grade 3 splenic injury. A contrast-enhanced computerized tomography (CT) scan performed in the hospital where she received primary treatment (4 hours after injury) showed non-enhancement of the left kidney with associated surrounding hematoma. A grade 3 splenic injury and peripheral rim sign were also present. No contrast was seen delineating the left ureter (Fig. 1). The right kidney was normal.

She was catheterized but had no hematuria, and urea/creatinine levels were also normal. Urine output over 24 hours was adequate. However, routine urine microscopy showed presence of 7 red blood cells (RBCs)/high power field (hpf) and was suggestive 

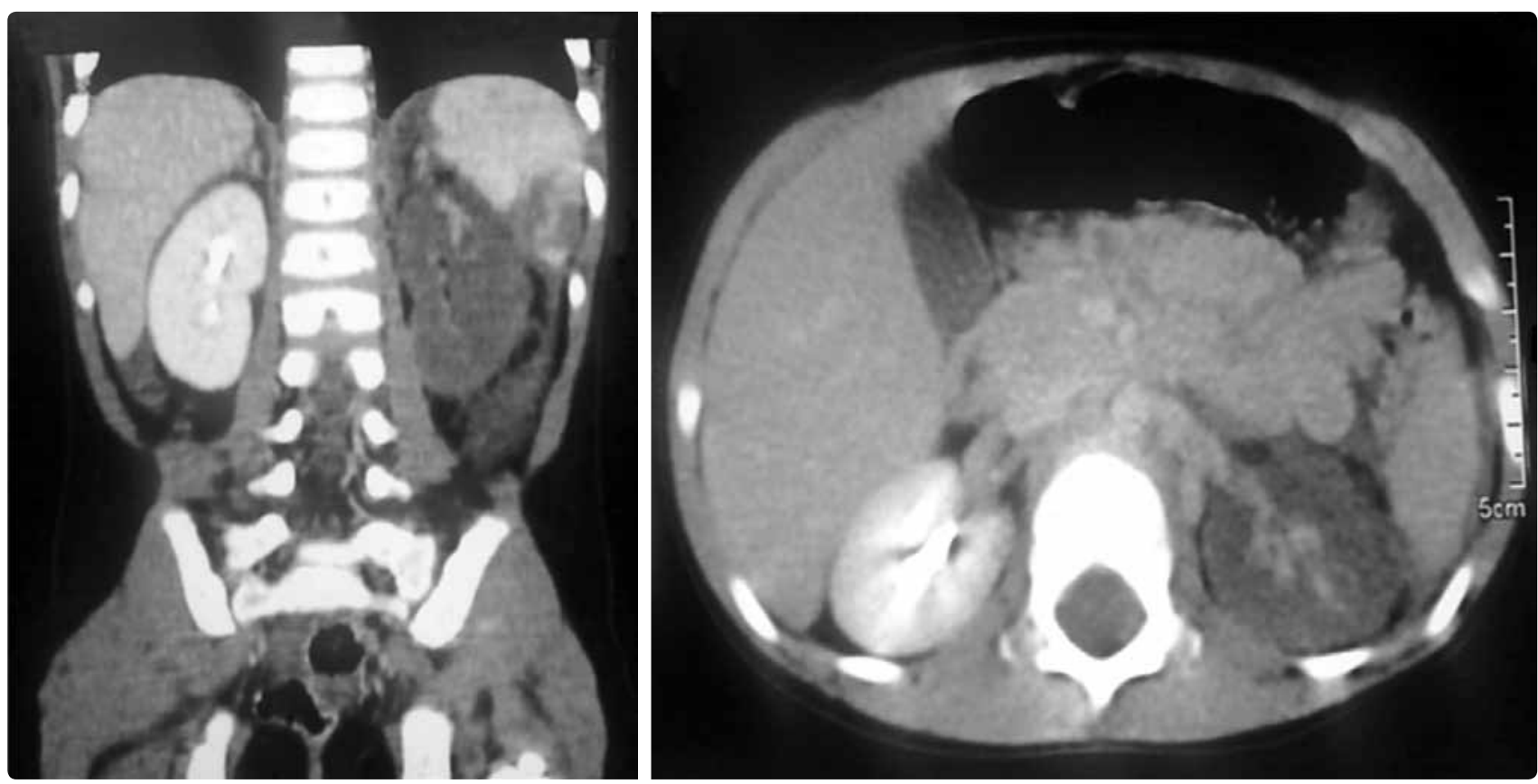

Fig. 1. CT scan showing non-enhancement of the left kidney.

of microscopic hematuria. Suspecting a diagnosis of renal artery occlusion and anticipating intervention, urgent intravenous urography (IVU), dimercaptosuccinic acid (DMSA) scan and CT angiography were done. IVU and DMSA showed the left kidney to be non-functional (Fig. 2). Ultrasound Doppler showed the left renal artery could be visualized to about $2 \mathrm{~cm}$ from its origin; however, distally for a length of $2 \mathrm{~cm}$ it was attenuated. Distally, few polar vessels were still seen. A CT angiography was done (50 hours after injury), which showed left renal artery occlusion for a length of approximately $1.1 \mathrm{~cm}$. The spleen showed presence of a $2 \times 2.4 \mathrm{~cm}$ intracapsular hematoma in the lower pole and pancreas, and other viscera were reported to be normal (Fig. 3).

Owing to the cost constraints, unilateral injury and delayed diagnosis, the child was managed conservatively. After a follow-up of one year, the child remains normotensive and had no febrile urinary tract infections. A repeat color Doppler showed maintained vascularity only in the upper pole of the left kidney. The follow-up DMSA scan showed cortical function only in the upper pole with a differential renal function of $8 \%$. The patient remains on regular follow-up for development of urinary tract infections and hypertension.

\section{DISCUSSION}

In children, trauma represents the single commonest cause of death, and injury to the kidney from blunt or penetrating trauma is the most common urinary tract injury. Traumatic renal artery occlusion in the pediatric age group is rare. Various large studies re- port the overall incidence of renal artery injuries as $0.05 \%,{ }^{[1]} 0.08 \%{ }^{[2]}$ and $0.1 \%{ }^{[3]}$ However, specific data on the incidence on the basis of age are lacking.

Traumatic renal artery occlusion is more common in the left and in individuals under 25 years of age, and bilateral involvement is extremely rare ${ }^{[1]}$ Children are more likely than adults to sustain major renal injury with lesser severity of trauma. The presence of decreased perirenal fat, weaker abdominal muscles and a less well-ossified thoracic cage offer less protection to the kidney. In addition, the larger size of pediatric kidneys in relation to the rest of the body, retention of fetal lobulations and presence of congenital anomalies may permit easier parenchymal disruption. ${ }^{[4]}$

A review of the literature showed very few pediatric patients with traumatic renal artery injury. Haas et al., ${ }^{[5]}$ in their series of 12 cases, had three pediatric patients. In another large series, by Elliott et al., ${ }^{[6]}$ no patient in the pediatric age group sustained main renal artery injury. Many other large series in the reviewed literature gave a mean age of presentation with no segregation of pediatric cases. ${ }^{[1]}$ Thus, there is a paucity of literature in pediatric traumatic renal artery occlusion. Gonzalez et al. reported nine conservatively managed pediatric cases. There are also three pediatric cases reported that were managed by endovascular treatment. ${ }^{[7-10]}$

The described mechanisms of injury that result in traumatic renal injury are acceleration/ deceleration injury of the comparatively fixed renal vascular pedicle, compression of the renal artery against the vertebral bodies of the spine, giving rise to intimal damage 

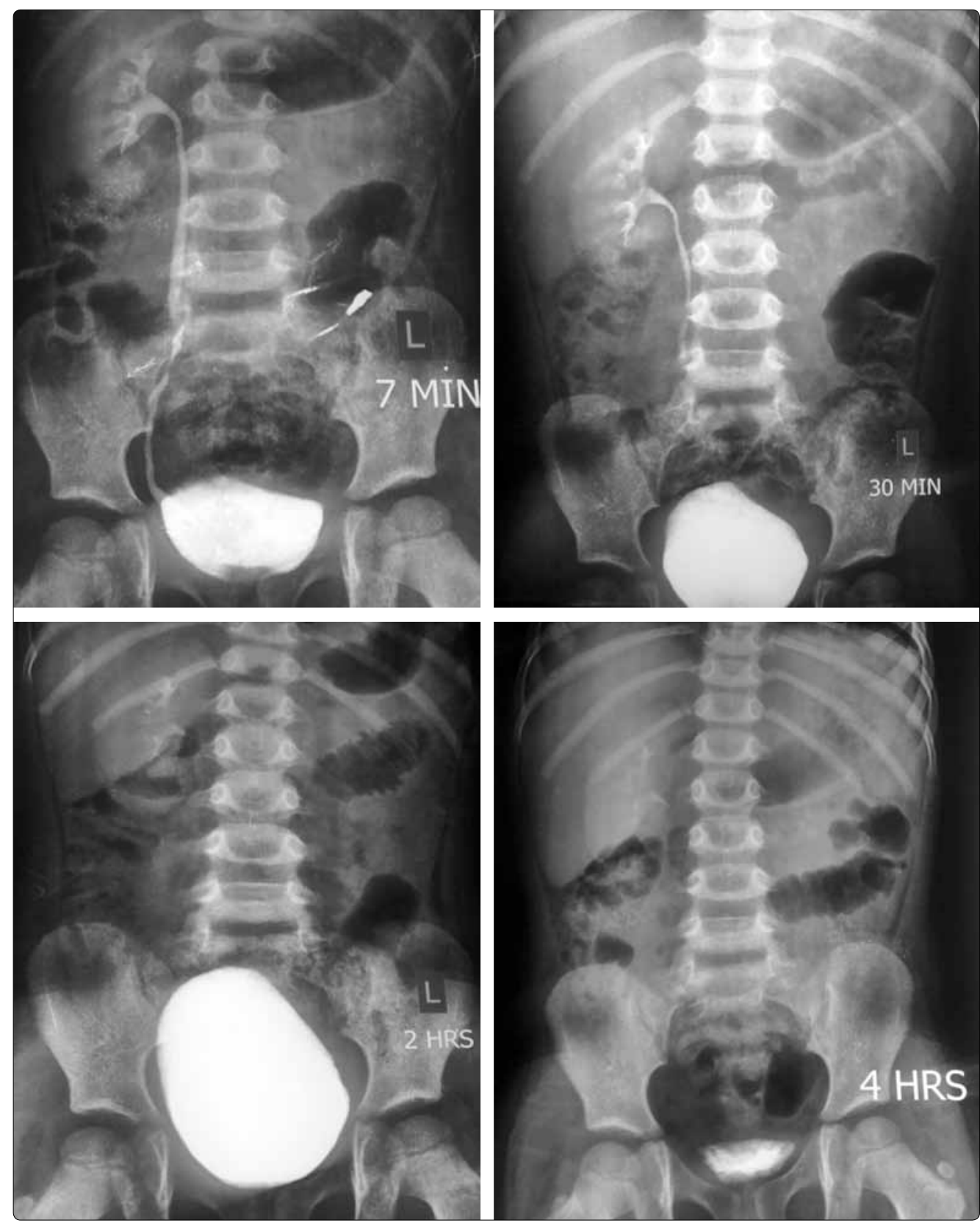

Fig. 2. Intravenous urography showing no contrast excretion by the left kidney.

of the vessel and thrombosis, and sometimes injury by fractured rib segments. ${ }^{[5]}$ Traumatic renal arterial thrombosis almost never occurs as an isolated event and indicates major associated injuries. ${ }^{[3]}$ The information on the physical examination is insufficient to establish a diagnosis. Flank bruising, proteinuria or hematuria may be observed, but are often nonspecific. ${ }^{[1-3,7]}$ Our patient had flank bruising but no gross hematuria. However, microscopic hematuria was found later.

Contrast-enhanced CT scanning is the modality of choice for diagnosis and follow-up after treatment of blunt traumatic renal artery occlusion ${ }^{[3,11]}$ Findings of the CT scan suggestive of renal arterial thrombosis include an absence of both renal parenchymal enhancement and contrast excretion in the affected kidney. Also, a thin rim of contrast enhancement, often described as the rim sign, may be noted ${ }^{[11]}$ Angiography is equally useful for predicting the blockade, and is the investigation of choice if segmental obstruction to the blood flow is present. However, angiography will not be helpful to rule out and delineate the extent of associated injuries like retroperitoneal hematoma. Instead, helical CT provides the diagnosis and predicts the level of blockade as well, in case revascularization is to be planned. ${ }^{[12]}$ In our case, we had ordered a contrast-enhanced $\mathrm{CT}$ with a $\mathrm{CT}$ angiography after 50 

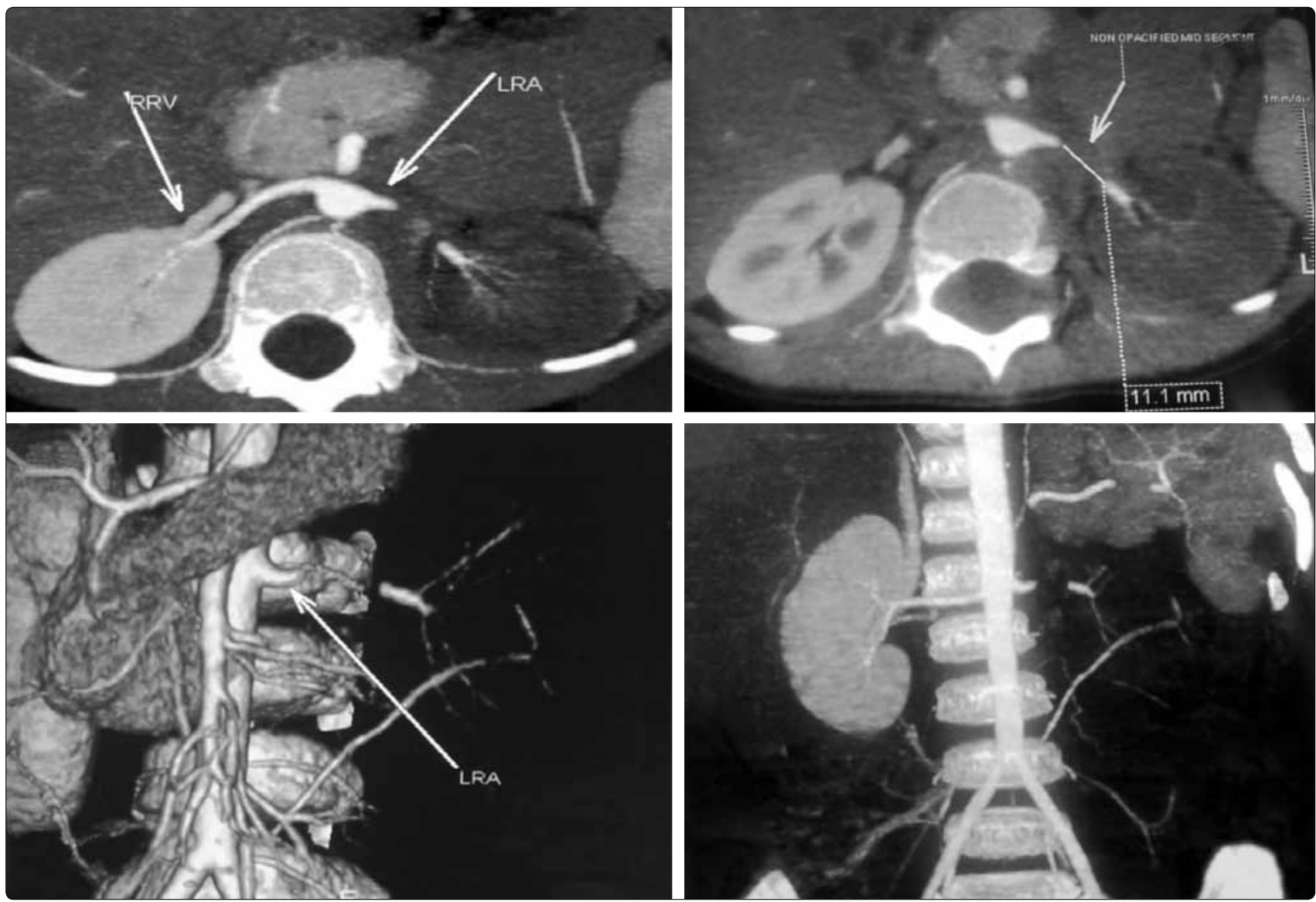

Fig. 3. CT scan showing left renal artery thrombosis.

hours of injury, anticipating intervention. In a center in which CT angiography is available, modalities like IVU and DMSA scans do not provide any additional information that can modify the intervention strategies in any way. However, it is important to document the non- functionality of the renal unit under consideration by various methods in order to avoid unnecessary litigations in medicolegal cases. The documentation becomes more important in cases here in India where the late referral is a very common reason for delay in appropriate intervention.

Anecdotal case reports suggest that severe time constraints influence successful revascularization of the occluded renal artery. Classically, it is thought that the kidney tolerates warm ischemia for only 1 hour. ${ }^{[2,3]}$ Successful revascularization has been reported within 24 hours and even 7 days post-injury, suggesting that, under rare and poorly understood circumstances, the kidney withstands longer periods of ischemia than generally believed. This occasional survival might be a result of incomplete occlusion of the renal artery or flow from collateral circulation. ${ }^{[10]}$

The optimal treatment for this entity is not well established and has been controversial. The rarity of the condition, delayed diagnosis, presence of other as- sociated life-threatening injuries or condition, and the disappointing long-term results of revascularization procedures are usually responsible for the lack of optimal treatment. Furthermore, in the Indian scenario, these patients are usually managed conservatively at set-up-lacking facilities and are later referred to higher centers for further management. This leads to loss of precious time, which plays a pivotal role in renal injuries and salvage of the jeopardized kidney. Our review of the literature has shown a definite change in trend from nephrectomies to preservation by revascularizations. With advances in radiology and resuscitative measures, the open revascularization procedures are preferably done by percutaneous means (mainly because of minimal invasiveness) in cases of both unilateral and bilateral traumatic renal artery occlusion, although the evidence for this sort of management comes mainly from case reports.

Treatment options include immediate surgical revascularization, nephrectomy and non-operative conservative therapy. ${ }^{[1-3]}$ Jawas et al. ${ }^{[3]}$ advocated conservative treatment in unilateral cases, with surgical revascularization required only in cases of bilateral injuries and injuries associated with solitary kidneys. The same is applicable to pediatric patients. Haas et al. ${ }^{[5]}$ in 
their series of 12 cases had three pediatric patients. In all three, revascularization was attempted, but resulted in nephrectomies in two and a differential function of $<10 \%$ in one who later developed hypertension.

Only three pediatric cases have been reported to have undergone endovascular treatment for renal arterial injuries. Halachmi et al. ${ }^{[8]}$ and Vidal et al. ${ }^{[10]}$ reported endovascular treatment in a renal artery pseudoaneurysm and Hsu et al. ${ }^{[9]}$ reported it in a renal artery pseudo-occlusion by an intimal flap. The procedure was successful in the cases with pseudoaneurysms, while in the latter, it was associated with shunt stenosis and nephrectomy.

The follow-up of these conservatively managed patients is very important, and includes scintigraphy scans to delineate the function in the conservatively managed kidneys. Another important issue is development of hypertension in these conservatively managed cases. About $25-50 \%$ of the patients will develop hypertension; most patients who develop renovascular hypertension do so within the fist year, with a mean of 96 days. $^{[5]}$ These patients may need delayed nephrectomy. However, the incidence of hypertension is less in pediatric cases of renal artery occlusion. In a retrospective study, Cortes-Gonzalez et al. ${ }^{[7]}$ reported hypertension to be present in only 2 of 9 pediatric cases reported. The reason for this may be age and absence of age- related vascular disorders already present before the time of trauma. The paucity of age-based literature makes it difficult to optimally answer this issue and raises a need for studies in larger series. However, close regular follow-up is required to assess the effect of conservative management on blood pressure.

In conclusion, traumatic renal artery occlusion in the pediatric age group is rare and under reported. The lack of age-based comparisons in larger series has led to the application of the same treatment algorithm as that used in adults. An age-related comparison among various factors with respect to the time of intervention, results of various procedures, and follow-up in the form of incidence of hypertension may provide some clues to the different management of this rare occurrence in pediatric age groups.

Conflict-of-interest issues regarding the authorship or article: None declared.

\section{REFERENCES}

1. Sangthong B, Demetriades D, Martin M, Salim A, Brown C, Inaba $\mathrm{K}$, et al. Management and hospital outcomes of blunt renal artery injuries: analysis of 517 patients from the National Trauma Data Bank. J Am Coll Surg 2006;203:612-7.

2. Bruce LM, Croce MA, Santaniello JM, Miller PR, Lyden SP, Fabian TC. Blunt renal artery injury: incidence, diagnosis, and management. Am Surg 2001;67:550-6.

3. Jawas A, Abu-Zidan FM. Management algorithm for complete blunt renal artery occlusion in multiple trauma patients: case series. Int J Surg2008;6:317-22.

4. Brown SL, Elder JS, Spirnak JP. Are pediatric patients more susceptible to major renal injury from blunt trauma? A comparative study. J Urol 1998;160:138-40.

5. Haas CA, Dinchman KH, Nasrallah PF, Spirnak JP. Traumatic renal artery occlusion: a 15-year review. J Trauma 1998;45:557-61.

6. Elliott SP, Olweny EO, McAninch JW. Renal arterial injuries: a single center analysis of management strategies and outcomes. J Urol 2007; 178:2451-5.

7. Cortés-González JR, Arratia-Maqueo JA, Garza-Cortés R, Gómez-Guerra LS. Is age a predictor for the development of hypertension in conservatively managed unilateral renal artery occlusion secondary to blunt abdominal trauma?. [Article in Spanish] Actas Urol Esp 2010;34:634-7. [Abstract]

8. Halachmi S, Chait P, Hodapp J, Bgli DG, McLorie GA, Khoury AE, et al. Renal pseudoaneurysm after blunt renal trauma in a pediatric patient: management by angiographic embolization. Urology 2003;61:224.

9. Hsu W, Mitchell SE, Kim HS. Renal artery stenting for intimal flap injury in a 2-year-old child after blunt abdominal trauma. South Med J 2006;99:884-7.

10. Vidal E, Marrone G, Gasparini D, Pecile P. Radiological treatment of renal artery occlusion after blunt abdominal trauma in a pediatric patient: is it never too late? Urology 2011;77:1220-2.

11. Kawashima A, Sandler CM, Ernst RD, Tamm EP, Goldman SM, Fishman EK. CT evaluation of renovascular disease. Radiographics 2000;20:1321-40.

12. Nuñez D Jr, Becerra JL, Fuentes D, Pagson S. Traumatic occlusion of the renal artery: helical CT diagnosis. AJR Am J Roentgenol 1996;167:777-80. 